\title{
SOME CURRENT ASPECTS OF PSYCHOSOMATIC RESEARCH
}

\author{
A. H. CRISP, M.B., D.P.M., M.R.C.P.E. \\ Lecturer, Academic Psychiatric Unit, Middlesex Hospital Medical School, London, W.I
}

Psychosomatic medicine is involving a rapidly expanding research field. The concept of emotional disturbance contributing to bodily disease is not a new one; however, it has only undergone systematic study during the last few decades. Evidence providing impetus towards its more general recognition accumulated during World War II when large numbers of people, often under uniform circumstances, had real and neurotic emotional stresses inevitably imposed upon them and sometimes appeared to react somatically (Grinker and Spiegel, 1945).

Emotional disturbance is thought to play a varying and sometimes indirect part in many illnesses ranging from infectious diseases (when it may determine the individual's motivation to exposure to infection and also some part of his subsequent resistance to it), to accidents and early tooth decay (Grinker, 196r). These broader implications will not be considered here and the concept will be limited to include only those conditions involving the viscera, cardio-vascular system, endocrine system, skin, and musculoskeletal system in so far as they are influenced-via the autonomic nervous system, endocrine and general motor nervous systems-by the visceral brain (Maclean, 1954) and hypothalamus. The major diseases thus usually included are peptic ulcer, ulcerative colitis, essential hypertension, migraine, various gynæcological disorders, urticaria, neurodermatitis, Raynaud's Disease, psoriasis, asthma, primary thyrotoxicosis, and rheumatoid arthritis.

In 1943 Halliday defined six criteria distinguishing psychosomatic disease. They are:

(I) The existence of an emotional disturbance as a precipitating factor;

(2) Some of the conditions are associated with a particular personality type;

(3) There is marked disproportion in the sex incidence in many of the conditions;

(4) The different conditions are associated and might be found together, alternating, or in sequence in the same person;

(5) There is often a family history of the same or similar disorder.

(6) The course of an individual disorder tends to be phasic with periods of remission and relapse.
It will be seen that these criteria apply equally to psychoneurotic illness.

Many physicians have remained sceptical of psychosomatic concepts when presented with purely psychodynamic and symbolic formulations (Jelliffe, 1922) and personality profiles (Dunbar, 1943) as the main vindication of psychosomatic theory. This early approach ensured that the general medical and psychiatric disciplines could rarely overlap or unite in this field since most general physicians do not have the training necessary to evaluate these factors, whilst the psychiatrists concerned have been handicapped by their lack of scientific method, the speculative element in psychoanalytic theory and the inevitable subjectivity in clinical assessments of personality. They have also usually worked on small groups of patients, rarely on whole populations and very rarely with controls. (Examples of good controlled studies include one in primary thyrotoxicosis by Mandelbrote and Wittkower in 1955, one in rheumatoid arthritis by King and Cobb in 1959, and one in peptic ulcer by Wretmark in 1953.)

This dichotomy of approach has led on the one hand to apparently authoritative reports such as that of the Empire Rheumatism Council (1950), a careful and controlled study by general physicians of 292 patients with rheumatoid arthritis in which they found no evidence of emotional stress as an ætiological factor, a finding which carries very little conviction for many psychiatrists. There are, on the other hand, gross speculative unverifiable psychodynamic formulations such as Allendy's (1932) regarding a case of eczema about which he feels able to say "Her hands were diseased that she might not kill her father and her husband. Her eczema was a punishment for her desires to masturbate and her illness gratified her primary wish for idleness'.

\section{Psychodynamic Hypothesis}

The personality types often described in patients regarded as suffering with psychosomatic disease are the dependent, the hostile dependent and the obsessional personalities. Attempts have been made to relate such types, with their characteristic emotional conflicts, to different forms of psychosomatic disease (Alexander and Szasz, 1952) since, from psychoanalytic theory, they 
derive from personality fixation at different infantile levels which are also associated with specific visceral needs and pleasures. It is during the neonatal and infantile periods of life that the visceral and musculo-skeletal responses, initially gross and mediated via diencephalic centres, and associated with the oral, anal and early social needs of the infant, begin to differentiate. It is suggested that varying degrees of frustration of, nongratification of, punishment of, and ambivalent attitudes to, the infant's needs during this period may induce a chronic admixture of fear and anger in the infant of varying relative intensities which comes to be associated with permanent overactivity of those visceral responses particularly associated with the inadequately gratified and therefore persistently active need(s). For example, gastric over-activity is said to be associated with unsatisfied hunger and the often associated failure by the mother to sufficiently love and comfort the child and make it feel secure (Alexander, 1950). Asthma is regarded as a more effective and potent parasympathetic secretory derivative of and alternative to the infant's ineffectual crying for securing the mother's attention (Turnbull, I962). Other factors determining organ choice may be a hereditary predisposition (Hamilton, Pickering, Roberts and Sowry, 1954, and Wretmark, 1953) and the relative loading of the differentiating visceral response at a critical time by infection or inhibition of one of its components; e.g., infantile gastro-enteritis, use of laxatives (Grinker, 1961), overfeeding, etc. Amongst the vast amount of work done on the psychopathology of these diseases there are a few studies of individual patients which are noteworthy (Alexander, 1939; Margolin, I95I; Groen, Van Der Valk and Bastiaans, I957; Stein, Kaufman, Janowitz, Levy, Hollander and Winkelstein, 1962).

Whatever the cause of the ultimate specific visceral response, these personality types have one feature in common; that is their special proneness to stress. This, rather than any special relationship between any one psychosomatic disease and personality type is emerging as a consistent and therefore more acceptable finding (Fox, I955). The dependent personality, probably more common now in our increasingly matriarchal society in which the father is no longer a dominant figure to whom the young child can relate away from the mother (Meerloo, 1956), is vulnerable to chronic anxiety over the loss-relative or complete-of specific mother figures; he cannot relate externally and satisfyingly to large numbers of people on the adult plane. The hostile dependent person is doubly vulnerable. Obsessional personalities are constantly tied to rigid behaviour patterns by the anxiety deriving from threatening subconscious aggressive and/or sexual impulses from within and may have aggression incorporated into their fran behaviour in a tightly bound form to control them selves and others. These groups are also prone to depressive illness and, in the latter two case paranoid reactions and breakdown. All these groups incorporate an excess of neurotic anxiet and/or anger into their personality from which they cannot free themselves effectively and which may be chronically severe and prone to acute exacerbations in unfavourable stressful circume stances. Their visceral and musculo-skelet $\vec{\phi}$ systems may be appropriately and differentially constantly charged.

\section{Emotional Stress}

Emotional stress is a difficult concept to definew. Overwhelming external threats can induce emo? tional stress in anyone, but disturbed personalities are also constantly exposed to threats from withing i.e., unrecognized and/or unsatisfied needs and drives, producing tension which cannot be effectively resolved. Attempts to define it were made at a conference of behavioural scientists a Oxford in $195^{8}$ when it was variously described ' a situation in which drives remain unsatisfied or expectations are not fulfilled; there is a mismafgct between the actual and the target (the 'is' and ' ought to be '), business is unfinished, problens are not resolved or there is a crisis-that is, sus pense in the taking of a decision'. The in dividual's maladaptive reaction to emotiona stress may be psychotic, psychoneurotic of psychosomatic (Hojer-Pedersen, 1958). In this context reaction-patterns in an individual pero sonality are not necessarily dynamically uniform and may comprise a variety of potential and actuat modes of reaction which find their widest expression in formal character disorder. Hence, ay emotionally-determined somatic response may be․ associated with total personality disturbance to. varying degrees and may be chronic or only bi revealed by very specific stresses. The psychoso 3 matic reaction may have a natural history como parable to that associated with the wide spectrum of psychoneurotic illness ranging from severe intractable mental ill-health associated with sever character disorder to the most fleeting of neurotio illnesses. In the former case it is likely to be associated with and alternate with other psychiatriow illness.

While the personalities described are obviousl particularly exposed to chronic emotional stress 诲 is possible that any person in whom anxiety of anger is excessively evoked for neurotic or non neurotic reasons may be prone to a psychosomatio response of pathological intensity (Mahl, 1950, Mah and Karpe, 1953, Mittleman and Wolf, 1942, an $\Phi$ 
Stenbäck, 1960). The complexity of factors operating, as a consequence of emotional stress, both directly on the organs concerned via the nervous system, and indirectly via the general adaptation mechanism (Selye, 1956) has been recognised as probably ultimately accounting for the diversity of possible visceral responses to emotional stress (Hamilton, 1955). Some workers have queried the validity of the concept of emotional disturbance provoking visceral response although they recognise a relationship between the two (Rostenberg, 1959). They claim that it is more reasonable to regard the body as an equally reacting whole. Some interesting work in this context (Russell and Last, I955) has shown that Besnier's prurigo is associated not only with cataracts but with EEG abnormalities, suggesting a general ectodermal distubance.

\section{Significance of Doctor-Patient Relationship}

All forms of treatment for the psychosomatic diseases are notorious for the unpredictability of their immediate and long-term effects in any one case. Psychiatric treatments have rarely systematically been attempted but on such occasions have sometimes given good results (MaherLoughnan, Macdonald, Mason and Fry, 1962, and Groen and Bastiaans, 195 I'). In all treatments the doctor-patient relationship is an intervening variable of unknown significance. The extent to which the doctor represents an ideal parent (for example, someone who approaches them with confidence, can be trusted, will love and protect them and keep them secure) should be of importance in this group of patients on the basis of most of the associated psychodynamic theories. Perhaps, for instance, it accounts for why two surgeons with similar operative techniques obtain vastly different results in the treatment and follow-up of cases of ulcerative colitis (Gabriel, 1953, and Aylett, 1957), also why some 'oral-dependent' patients who are heavy smokers as well as suffering from peptic ulcer are able to gain relief through the relationship from both these states, which might then be regarded as co-variables and not cause and effect. Recent work on a measure of this relationship (Crisp, 1963) has already suggested that psychoneurotic patients idealize their doctors in this way to a considerable degree.

Margolin (I95I), who studied a patient with a gastric fistula both physiologically and psychoanalytically, considered that her gastric activity at any one time was closely related to the extent to which the analytic transference (an extension of the doctor-patient relationship) was satisfying her emotional needs. More recently, Knowles and Lucas (1962) have demonstrated, in a group of patients, that a measure obtained of their attitude to doctors correlates quite highly with the patient's rating of the beneficial effects of treatment.

\section{Clinical Studies}

There have been many recent research advances at a clinical level in specific psychosomatic diseases. These have mostly been made in the U.S.A. and have often been concerned with the investigation of physiological and clinical variables in patients exposed to known emotionally stressful situations. In his now classical studies Wolff has shown the sensitivity of the gastric (Wolf and Wolff, 1943) and colonic (Grace, Wolf and Wolff, 1950) mucosæ to states of induced anxiety and anger. This technique, of producing disturbed emotional states in patients, usually during psychotherapy, and observing and measuring clinical changes has since been widely employed, particularly in studies on urticaria, neurodermatitis, Raynaud's disease, essential hypertension, rheumatoid arthritis, and asthma. Elaboration of this work is beyond the scope of a short article but it is adequately surveyed in the standard books and reviews. Other recent clinical studies of a slightly different nature include one by Weiner, Thaler, Reister and Minsky (1957) in which they made accurate predictions of the development of peptic ulcer amongst trainee soldiers on the basis of personality studies only, and work by Kaplan and Gottshalk (1958) in which they demonstrated changes in the bacterial flora of the mouth and throat with changes in emotional state.

Clinical research in this country has been mainly concerned in attempts to measure valid personality variables amongst, or make controlled psychiatric assessments of, groups of medically-ill patients. Sainsbury (1960) studied one large group of general hospital out-patients and with their illnesses already firmly diagnosed. He tested these patients on the highly standardized Maudsley Personality Inventory (MPI). He found that most of the so-called psychosomatic diseases were associated with significantly high scores on neuroticism and that these patients were usually less extrovert, again often statistically significantly so, than normals. He correctly predicted many of his results. Culpan, Davis and Oppenheimer (I960) using the Cornell Medical Index, also studied outpatients attending medical, surgical, gynæcological and physical medicine clinics in a big London hospital. They concluded that emotional disturbance tended to be high in these groups, particularly so in the latter two groups and in women attending surgical out-patients. In addition they showed that emotional disturbance was high in women attending the gynæcological out-patients, whether they were new or long-standing patients, thus going some way to showing that the emotional 
upset was not secondary to the physical one in this group. This important issue, of the temporal relationship of the emotional and somatic illnesses, requires longitudinal studies. It is referred to in relation to peptic ulcer by Hojer-Pederson (1958) in his extensive study of a group of patients. Other work, using the MPI, includes Coppen's (1958, 1959) studies of gynæcological and obstetric disorders, and Kenyon's (1962) study of skin diseases. There have been some carefully controlled studies on groups of asthmatics by Leigh (1956) and Rees (1956a, 1956b) which have confirmed the widespread importance of psychological factors in this condition. Rees has found similar significances in urticaria (1957) and hay fever (1959). Approaching the problem in the reverse way, Gosling (1958) has studied the incidence of peptic ulcer amongst psychiatrically-ill patients. He combines a psychoanalytical approach with methodical study to show that neurotics are more prone to peptic ulcer than normals and that, amongst the neurotics, the incidence is significantly high compared with normals when there are depressive features; also he found the incidence to be significantly high amongst alcoholics. He suggests that the stress deriving from neuroticism plus the particular oral-dependent traits revealed by the depressive reaction and the alcoholism are the factors that also render these individuals vulnerable to peptic ulcer. In Scandinavia, Wretmark (1953), in part of an authoritative study has surveyed the evidence for the existence of genetic and environmental determinants in peptic ulcer. He notes that patients with duodenal ulcer are more often leptosomatic (using Stromgren's Index) in body build than matched controls. Body build, as measured over a larger variety of physical attributes, has some correlation with personality types and neurotic illness. However, it is a less accurate measure of these factors than the more direct methods of assessing personality (Rees, 1960).

\section{Animal Studies}

Experimental work in animals has revealed many interesting results which are limited in their usefulness, particularly because of species specificity. Masserman (1959) describes all manner of somatic responses in animals subject to experimental neurosis. Amongst a great deal of work done on peptic ulcer in animals (Wener and Hoff, I948), that by French, Porter, Cavanaugh and Longmire (1957) in which they induced peptic ulcers in monkeys following appropriate hypothalamic stimulation, is notable. In the field of ulcerative colitis Lium and Porter (I939) have demonstrated that, in dogs at least, colonic spasm can lead on to ulcer formation. Liddell (1960) has induced experimental neurosis in recently born lambs and kids by varying degrees of conditioning and separation from the mother. Such animals apart from their neurotic behaviour, often fail to thrive; suffer excessively with other diseases, abort their young and die young. Those subject to the most severe stresses revealed hæmorrhagic adrenat cortices at autopsy. Early forced separation froro the mother is highlighted in this work as being associated with the most serious consequences and early death. Hinds (1959, 1960) has studied the social stress factors which can operate betweef various animals and their effect on autonomico response and illness; animals under these stresse $\overrightarrow{\mathbf{s}}$ sometimes develop apparently purposeless ans fixed autonomic responses, and are prone to illnesg and early death.

\section{Physiological Variability}

One last field of research with humans appear most fruitful. The earlier research described had served to show the importance of emotional factors in autonomic nervous system and endocrine (especially adrenal gland) activity in patients. During the last decade more refined methods $\vec{q}$ measurement of adrenal gland metabolites an more accurate measures of general autonomic activity have been developed. This has permigeed and encouraged more careful and systematic studies of these functions in wider groupso people, healthy and ill, at rest and subject simple and more quantifiable forms of stress.

Following von Euler's (1953) early work Elmadjian, Hope and Lamson (I957) have studiec adrenaline and noradrenaline excretions in normas undergoing physical and emotional stress and psychiatric patients undergoing psychotherapy They claim to have shown that active aggressive hostile behaviour is accompanied primarily by the enhancement of noradrenaline excretion, white anxious, passive behaviour primarily results enhanced adrenaline excretion. The difficulty with these experiments is in controlling and objectifying the amount and type of stress. For instance, Elmadjian himself has found and as Dittes (195\%) has also shown in the studies on patients in psychotherapy, the responses are related not onty to the discussion of emotionally charged materia from the patients' past but also on the immediate interrelation of the patient and doctor.

The response of the adrenal cortex to acute and chronic physical and emotional stress has beeg studied in many centres (Hoagland, 1960; Elmad jian, 1955; Davis, Morrill, Fawcett, Upton, Bond and Spiro, 1962; Fox, 1955; Brit. med. F., 195珤 Brit. med. F., 1958); Persky's group (1957a, r.957 b 1959) in particular have carried out a series of careful studies in which they have demonstrated the responsiveness of the adrenocortical function 
to states of neurotic and experimentally induced anxiety.

A number of aspects of autonomic activity other than respiratory rate, heart rate, and blood pressure, can now be measured fairly accurately; e.g. skin temperature, skin resistance, finger volume, palmar sweating, muscle tension, gastric motility. Sternbach (1962) has measured such variables during changing emotional states in children and finds, in a pilot study, that states of happiness seem to be associated with significantly decreased gastric peristaltic activity, and states of sadness with increased skin resistance. Shagass and Malmo (1954) found high muscle tension to be localized to the arms or legs depending on whether aggressive or sexual conflicts were being discussed with patients. Numbers of similar experiments have recently been conducted on patients in psychotherapy. A high correlation is usually shown between the changing intensity of affective experience and magnitude of various autonomic variables and sometimes qualitative relationships have been demonstrated. This work is reviewed by Lacey (I959).

Working with normals, Davis and Buchwald (1957) have studied the response of 12 autonomic variables to affectively charged stimuli. Their results show that the traditional concept of parasympathetic versus sympathetic response is an oversimplification and that, for instance, in a given test situation, increased muscular tension, widespread vasoconstriction and palmar sweating are consistently associated with cardiac deceleration, not acceleration; such constellations of response vary significantly with the stimulus and between the sexes. Lacey's own work, also covered in his review (1959), has served to demonstrate something of the more basic nature of general and individual autonomic responsiveness. The intensity of autonomic response depends partly on the pre-stimulus tension or tone within the system; in addition the system seems prone to bursts of spontaneous activity of an individually specific nature and probably related to established ' hyperkinetic-impulsive' aspects of behaviour (Lacey and Lacey, 1958a). He has also shown that, at any one time, correlations between specific autonomic measures are much lower than would be expected by conceiving of some aggregate response operating along a simple parasympatheticsympathetic continuum (Lacey and Lacey, 1958b). It is now recognized that there is considerable individual variability in the responsiveness of individual autonomic functions to a simple stress in the experimental situation; for instance, one person responds with tachycardia and no change in palmar conductance, the reverse is observed in another person. Hence, no one measurement is a generally reliable indicator of autonomic tone or change. In any one person, however, the responses seem consistent and in a longitudinal study in children he has shown (1959) that some specific modes of autonomic reaction are stereotyped in this way by the age of 6 . Furthermore, in Lacey's work, the pattern of response, over the few variables measured, was similar with various stressors regarded as being different in their physiological and psychological demands. He is able to some extent to differentiate these two demands both of which he recognizes can operate, however simple the stimulus.

If, at a clinical level, the degree of autonomic responsiveness and type of stereotopy are thought to indicate the individual's predisposition to psychosomatic disease and its parcicular manifestations respectively-then this may prove a most valuable research field. Perhaps, as Hill (1963) suggests, we shall soon know whether these factors, and particularly stereotopy which determines ' organ choice ', are inherited or acquired characteristics. Family and twin studies, using Lacey's techniques, are necessary for this.

\section{Summary}

The whole concept of psychosomatic disease remains unproven. Halliday's criteria have proved useful clinically but have limited heuristic value. From the clinician's point of view, there is no doubt that individual psychosomatic illnesses are often associated with severe emotional upset and this relationship has frequently been reproduced experimentally. Clinical genetic studies which might provide some of the answers are as yet incomplete. The notion that it is possible to describe specific personality profiles associated with different diseases is no longer tenable. The related psycho-dynamic hypotheses regarding the relationship of various infantile conflicts to early visceral activity remain as unproven in this field as they do in respect of the psychoses generally. The concept of emotional stress remains to be clearly defined; reliable means must be developed of detecting and quantifying it. Such stress can probably derive either mainly from within the individual, as a consequence of inner emotional conflict, or else mainly be the result of social pressures.

The idea that these diseases result from some abnormal autonomic or endocrine participation in reaction to stress appears a most fruitful research field. In this respect the work described towards the end of this paper would seem very important. Finally, if this is shown to be the case, it will remain to be shown whether this is an abnormal learned or genetically determined response. 
Alexander, F. (1939): Psychoanalytic Study of a Case of Essential Hypertension, Psychosom. Med., r, r39.

(1950): 'Psychosomatic Medicine'. New York: Norton.

, and Szasz, T. (1952): The Psychosomatic Approach in Medicine, 'Dynamic Psychiatry'. Eds. Alexander, and Ross, H. Chicago: University Chicago Press.

Allendy, R. (1932): A Case of Eczema, Psychoanal. Rev., 19, 152.

AyletT, S. (1957): Total Colectomy and Ileo-rectal Anastomosis in Diffuse Ulcerative Colitis, Brit. med. Y., i, 489을

British Medical fournal (1956): ii, 592. (1958): Adaptation to Stress, ii, 382 . (1958): ii, 496.

Coppen, A. J. (1958): Psychosomatic Aspects of Pre-eclamptic Toxæmia, \}. psychosom. Res., 2, 241.

(1959): Vomiting and Pregnancy, Lancet, i, 172.

CrisP, A. H. (1963): In press.

Culpan, R., Davis B., and OpPenheimer, A. (1960): Incidence of Psychiatric Illness Amongst Hospital Out-Patients, Brit. med. $\boldsymbol{F} .$, i, 855 .

Davis, J., Morrill, R., Fawcett, J., Upton, V., Bondy, P. K., and SPIro, H. M. (1962): Apprehension and Elevatef Serum-cortisol Levels, $\mathcal{F}$. psychosom. Res., 6, 2 and 83.

Davis, R., and Buchwald, A. (1957): An Exploration of Somatic Response Patterns: Stimulus and Sex Differenç8, F. comp. physiol. Psychol., 50, 44.

Ditres, J. E. (1957): Galvanic Skin Response as a Measure of the Patient's Reaction to Therapists Permissiveness, F. abnorm. soc. Psychol., 55, 295.

Dunbar, F. (1943): ‘ Psychosomatic Diagnosis'. New York: Hoeber.
Elmadjian, F. (1955): Adrenocortical Function of Combat Infantrymen in Korea. Ciba Colloquia on Endocrinologf, 8, 627. London: Churchill.

- Hope, J., and LAMSON, E. (1957): Excretion of Epinephrine and Norepinephrine in Various Emotional States, Ұ. clin. Endocrin., 17, 608.

Empire Rheumatism Council (1950): Scientific Advisory Committee, Brit. med. F., i, 799.

Euler, U.S. voN (1953): Distribution and Possible Physiologic Function of Epinephrine and Norepinephrine, Trafs. 6th Conf. Macy Foundation. Ed. Green, H. D. New York: Macy.

Fox, H. M. (1955): Psychological Influences on the Adrenal Gland, Ciba Colloquia on Endocrinology, 8, 6r2. Londog : Churchill.

French, J. D., Porter, R. W., Cavanaugh, E. B.; and Longmire, R. L. (1957): Experimental Gastro-duodenal Lesion Induced by Stimulation of the Brain, Psychosom. Med., 19, 209.

Gabriel, W. B. (1953): Discussion, Proc. roy. Soc. Med., 46, I035.

Gosling, R. (1958): Peptic Ulcer and Mental Disorder I and II, $\mathscr{F}$. psychosom. Res., 2, 190 and 285.

Grace, W. J., Wolf, S., and WolfF, H. G. (1950): Life Situations, Emotions and Colonic Functions, Gastroenter $\mathscr{E}$ I4, 93 .

Grinker, R. R., and SpIEgel, J. P. (1945): 'Men under Stress'. Philadelphia: Blakiston.

Grinker, R. R. (196r): 'Psychosomatic Research', p. 94. New York: Grove Press Inc.

Groen, J., and BastiaAns, J. (195 I): Psychotherapy of Ulcerative Colitis, Gastroenterology, $17,344$.

-, VAN Der Valk, J., and BastiaAns, J. (1957): A Case of Malignant Hypertension, $\mathcal{F}$. psychosom. Res., $2,120$.

Halliday, J. L. ( I943): Concept of a Psychosomatic Affection, Lancet, ii, 692.

Hamilton, M., Pickering, G., Roberts, J., and Sowry, G. (1954): The Ætiology of Essential Hypertension: 4. T Role of Inheritance, Clin. Sci., r3, 273.

Hamplton, M. (1955): 'Psychosomatics', p. 202. London: Chapman and Hall.

Hill, D. (1963): In press.

HiNDE, R. A. (I959): 'The Nature of Stress Disorders ', p. 94. London: Hutchinson.

(1960): 'Stress and Psychiatric Disorder', p. 49. Ed. Tanner, J. M. Oxford: Blackwell Scientific Publications.

Hoagland, H. (r960): 'Stress and Psychiatric Disorder', p. 85. Ed. Tanner, J. M. Oxford: Blackwell Scientific Publications.

Hojer-Pedersen, W. (1958): On the Significance of Psychic Factors in the Development of Peptic Ulcer, Acta psychiat. scand., Suppl. 119.

Jelliffe, S. E. (1922): Psychopathology and Organic Disease, Arch. Neurol. Psychiat. (Chicago), 8, 639.

Kaplan, S. M., and GotTshalk, L. A. (1958): Modifications of the Oropharyngeal Bacteria with Changes in the Psychodynamic State, 2, Psychosom. Med., 20, 314.

KenYon, F. E. (1962): A Psychiatric Survey of a Random Sample of Out-patients Attending a Dermatological Hospitit, F. psychosom. Res., 6, 2, 129.

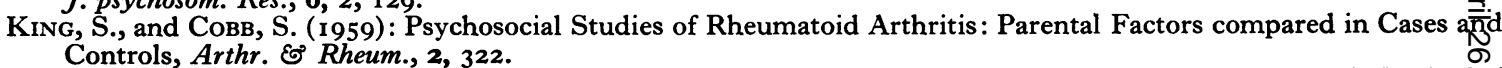

Knowles, J. B., and LuCas, C. J. (1962): The Contribution of Attitude and Personality to the Patient's Rating ${ }^{\prime}$ Treatment, Proc. roy. Soc. Med., $55,778$.

LACEY, J., and LACEY, B. (1958a): 'The Brain and Human Behaviour', chap. 36, p. 144. Baltimore: Williams a Jd $^{2}$ Wilkins.

$-,-\frac{1}{1958 b): ~ V e r i f i c a t i o n ~ a n d ~ E x t e n s i o n ~ o f ~ t h e ~ P r i n c i p l e ~ o f ~ A u t o n o m i c ~ R e s p o n s e ~ S t e r e o t o p y, ~ A m e r . ~ F . ~ P s y c h o ̈ ., ~}$

71, 50.
(1959): Psychophysiological Approaches to the Evaluation of Psychotherapeutic Process and Outcome, 'Reseageh
in Psychotherapy', American Psychological Association, Washington, D.C., p. I60. in Psychotherapy ', American Psychological Association, Washington, D.C., p. I60.

Leigh, D., and Marley, E. (1956): A Psychiatric Assessment of Adult Asthmatics: A Statistical Study, F. psychosoon. Res., $1,128$.

LidDell, H. S. (1960): 'Stress and Psychiatric Disorder', p. 59. Ed. Tanner, J. M. Oxford: Blackwell Scient满ic Publications.

Lium, R., and Porter, J. (1939): Ætiology of Ulcerative Colitis, Arch. intern. Med., 63, 201. 
MacLean, P. D. (1954): Studies on the Limbic System (Visceral Brain) and their Bearing on Psychosomatic Problems 'Recent Developments in Psychosomatic Medicine'. Eds. Wittkower and Cleghorn, R. Philadelphia: J. B. Lippincott.

Maher-Loughnan, G., Macdonald, N., Mason, A., and Fry, L. (1962): Controlled Trial of Hypnosis in the Symptomatic Treatment of Asthma, Brit. med. F., ii, 371 .

Mahl, G. F. (1950): Anxiety: HCL Excretion and Peptic Ulcer Etiology, Psychosom. Med., 12, 158.

-, and KARPE, R. (1953): Emotions and HCL Secretions during Psychoanalytic Interviews, Ibid., r5, 312.

Mandelbrote, B., and WitTKower, E. (1955): Emotional Factors in Graves Disease, Ibid., I7, 109.

Margolin, S. G. (195I): The Behaviour of the Stomach during Psychoanalysis, Psychoanal. Quart., $20,349$.

MASserman, J. H. (1959): The Biodynamic Approaches, 'American Handbook of Psychiatry', 2, 1680. New York: Basic Books Inc.

Meerloo, J. A. (1956): The Father Cuts the Cord, Amer. F. Psychother., ro, 47 I.

Mittleman, B., and Wolff, H. G. (1943): Emotions and Gastro-duodenal Function, Psychosom Med., $4,5$.

Persky, H. (1957a): Adrenocortical Function in Anxious Human Subjects, $\mathcal{F}$. clin. Endocrin., I7, 760.

(1957b): Adrenocortical Function in Anxious Human Subjects, A.M.A. Arch. Neurol. Psychiat. (Chicago), 78, 95. , Gros, H., Norton, J., and McMurTry, M. (1959): Effect of Hypnotically Induced Anxiety on the Plasma Hydrocortisone Level of Normal Subjects, $\mathcal{F}$. clin. Endocrin., 19, 700.

REes, L. (1956a): Physical and Emotional Factors in Bronchial Asthma,, , psychosom. Res., r, 98.

(1956b): Psychosomatic Aspects of Asthma in Elderly Patients, Ibid., I, 212.

(1957): An Ætiological Study of Chronic Urticaria and Angio-neurotic WEdema, Ibid., $2,172$.

- (1959): The Role of Emotional and Allergic Factors in Hay Fever, Ibid., 3, 234. (1960): Constitution and Neurosis, 'Advances in Psychosomatic Medicine', vol. I, page ro6. Basel: S. Karger

Rostenberg, A. (r959): Psychosomatic Concepts in Atopic Dermatitis: a Critique, A.M.A. Arch. Derm., 79, 692.

Russell, B., and LAST, S. L.(1955): Besnier's Prurigo: Observations on Abnormal Cutaneous and Central Nervous Reactions, Brit. F. Derm., 67, 65.

Sainsbury, P. (1960): Neurosis and Psychosomatic Disorders in Out-patients, 'Advances in Psychosomatic Medicine', vol. I, p. 259. Basel: S. Karger A.G.

Selye, H. (1956): 'The Stress of Life'. New York: McGraw Hill.

Shagass, C., and Malmo, R. (1954): Psychodynamic Themes and Localized Muscular Tension during Psychotherapy, Psychosom. Med., 16, 295.

Stein, A., Kaufman, M., Janowitz, H., Levy, M., Hollander, S., and Winkelstein, A. (I962): Changes in HCl Secretion in a Patient with a Gastric Fistula during Intensive Psychotherapy, Ibid., $24,427$.

Stenback, A. (1960): Gastric Neurosis, Pre-ulcer Conflict, and Personality in Duodenal Ulcer, $\mathcal{F}$. psychosom. Res., 4, 282 .

SteRnBäch, R. (1962): Assessing Differential Autonomic Patterns in Emotions, Ibid., 6, 87.

TuRnbull, J. W. (1962): Asthma Conceived as a Learned Response, Ibid., 6, 59.

Weiner, H., Thaler, M., Reister, M. F., and Minsky, I. A. (1957): Ætiology of Duodenal Ulcer, Psychosom. Med., I9, I.

WeNER, J., and Hoff, H. E. (1948): The Neurochemical Aspects of Peptic Ulcer Formation, Canad. med. Ass. F., 59, I 15. Wolf, S., and WolfF, H. G. (1943): 'Human Gastric Function'. New York: Oxford.

Wretmark, G. (1953): The Peptic Ulcer Individual: A Study in Heredity, Physique and Personality, Acta psychiat. scand., Suppl. 84 . 